\title{
O político na constituição do discurso do sujeito Xukuru do Ororubá: educação, memória e luta
}

\author{
José Reginaldo Gomes de Santana ${ }^{1}$ \\ Nadia Pereira da Silva Gonçalves de Azevedo ${ }^{2}$ \\ Acolhe seu filho, minha mãe natureza. Ele não \\ vai ser enterrado (...) Ele não vai ser sepultado, e sim \\ ele vai ser plantado para que dele nasçam novos \\ guerreiros, minha mãe natureza! ${ }^{3}$ \\ (Zenilda Araujo, Xicão Xukuru)
}

Resumo: O artigo trata de analisar o discurso político do sujeito-aluno Xukuru do Ororubá em um lugar outro não circunscrito ao seu território. Para isso, utilizamos o dispositivo teóricometodológico da Análise do Discurso de Linha francesa, filiada ao pensamento de Michel Pêcheux e com desdobramentos, no Brasil, a partir de Eni Orlandi. Nesse espaço outro, o discurso do sujeito-aluno Xukuru ganha novos sentidos em condições de produção diversas, mas ainda o que é memorável nos saberes dos discursos fundantes permanece mobilizando sentidos e sujeitos. Isso em razão da constante luta política desse povo na estrutura e na conjuntura político-econômico-social nacional vigente.

Palavras-chave: Discurso. Memória. Xukuru. Educação.

Abstract: The article analyzes the political discourse of the subject-student Xukuru of the Ororubá in a place other not circumscribed to its territory. For this, we used the theoreticalmethodological device of the French Discourse Analysis, affiliated to the thought of Michel Pêcheux and with developments in Brazil from Eni Orlandi. In this other space, the discourse of the subject-student Xukuru gains new meanings in diverse production conditions, but still what is memorable in the knowledge of the foundational discourses remains mobilizing senses and subjects. This is due to the constant political struggle of these people in the structure and current national political-economic-social conjuncture.

Keywords: Discourse. Memory. Xukuru. Education.

\footnotetext{
${ }^{1}$ Professor de Música do IFPE Campus Pesqueira e Doutorando em Ciências da Linguagem Unicap.

2 Pesquisadora e Professora do Programa de Pós Graduação em Ciências da Linguagem da Universidade Católica de Pernambuco - Unicap. Doutora em Letras e Linguística pela Universidade Federal da Paraíba

${ }^{3}$ Fala de Zenilda Araújo no sepultamento do seu marido Xicão, Cacique dos Xukuru de Ororubá, no documentário Xicão Xukuru (1999).
} 
Résumé: L’article tente d'analyser le discours politique de l'élève-sujet Xukuru des Ororuba dans un lieu non circonscrit à son territoire. Pour cela, nous utilisons le dispositif théoriqueméthodologique de l'Analyse du discours de la langue française, affilié à la pensée de Michel Pêcheux et se déroulant au Brésil, chez Eni Orlandi. Dans cet autre espace, le discours sujetétudiant Xukuru acquiert de nouvelles significations dans diverses conditions de production, mais ce qui reste mémorable dans la connaissance des discours fondateurs reste la mobilisation des sens et des sujets. Cela est dû à la lutte politique constante de ces personnes dans la structure et à la conjoncture politique, économique et sociale nationale actuelle.

Mots-clés: Discours. Mémoire. Xukuru. Éducation.

\section{Introdução}

Este trabalho analisa o discurso político do sujeito-aluno Xukuru do Ororubá em uma posição que é construída, simultaneamente, através do efeito do dizer do "já constituído" Sujeito Indígena, em seu território, com o dizer do Sujeito Xukuru em um lugar outro - instituição de ensino não indígena, não circunscrita à Serra do Ororubá (localizada no Agreste de Pernambuco, na cidade de Pesqueira). O discurso construído em torno da luta do Cacique Francisco de Assis Araújo, "Xicão", pela demarcação da terra, das palavras ditas durante essa empreitada, do seu assassinato e dos dizeres sobre este fato constitui grande parte dos saberes determinantes do discurso do Sujeito Xukuru de Ororubá. É sobre o funcionamento desse discurso, a partir de dizeres de alunos indígenas, numa instituição não indígena de ensino, que esse artigo trata.

\section{Dispositivo teórico-metodológico}

$\mathrm{Na}$ fundamentação teórica, mobilizamos os conceitos de conjuntura política e de exterioridade (ORLANDI, 2014), de arquivo (PECCHEUX, 2010) e de memória discursiva (COURTINE, 2009). O corpus deste trabalho é formado por arquivos de vídeos - documentários, reportagens e informativos institucionais - que apresentam 
dizeres do Xukuru em diferentes condições de produção: tanto na luta pela terra como em outras posições.

Entendemos os documentos e os vídeos do corpus como um arquivo, como “campo de documentos pertinentes e disponíveis sobre uma questão" (PÊCHEUX, [1982], 2010, p. 51). Assim como Romão, Leandro-Ferreira e Dela-Silva (2011, p. 13), entendemos que, na leitura de um arquivo, há a necessidade de considerar a questão sobre sua gestão/constituição: “documentos 'pertinentes' a quem, e 'disponíveis' a quem, em que condições sócio-históricas e ideológicas?”. Para Borges (2013, p. 256), “o interdiscurso e o arquivo são dois modos distintos de funcionamento da memória discursiva. Enquanto o interdiscurso se estrutura pelo esquecimento, o arquivo é o que não se esquece ou o que não se deve esquecer".

O dispositivo teórico-metodológico que utilizamos é calcado na Análise do Discurso de Linha Francesa, filiada ao pensamento de Michel Pêcheux e com desdobramentos no Brasil a partir de Eni Orlandi. A análise discursiva deste trabalho parte dos marcos históricos fundantes apresentados por Silva (2008, 2011), que abrangem a história e as memórias desse povo, passa pela relação de arquivo e memória discursiva como também pelo funcionamento do político no trabalho dessa relação, no silenciamento, deslizamento e regularização de sentidos.

Entendemos, como Orlandi $(2014)^{4}$, que a conjuntura política e a ideologia produzida pelo sistema vigente do país ultrapassam a esfera governamental, abarcando “toda sociedade e instituições” (ORLANDI, 2014, p. 113). Os efeitos do político nas instituições têm relação com a exterioridade constitutiva dos discursos que circulam por elas, "têm a ver com o modo como o político se instala na formação social e aí produz seus efeitos”, (...) nas "articulações complexas com a forma como o político dominante se significa na sociedade e na história" (ORLANDI, 2014, p. 112). De fato, a ideologia constitui os sentidos e os sujeitos, porém ela também produz resistências.

\section{Análise discursiva}

\footnotetext{
${ }^{4}$ Orlandi (2014, p. 17), nessa obra, trata sobre a Análise de Discurso e Projetos sobre e da Língua Portuguesa nos anos 1960/1990, sobre o conhecimento linguístico e as formas do político, sobre como o Estado administra o político afetando a sociedade e as instituições, sobre "como somos significados e nos significamos" pelas relações de poder geridas pelo Estado.
} 
Entendemos que as sequências discursivas que fazem parte de nossa análise são oriundas dos efeitos do político tanto nas instituições, nos sujeitos e na sociedade, quanto nos gestos dos analistas na construção do corpus. Uma relação inicial com o objeto deste trabalho nasceu de uma experiência do primeiro autor deste artigo no seu primeiro dia de seleção de concurso para professor do Centro Federal Tecnológico de Pernambuco - Unidade Pesqueira (CEFET Uned Pesqueira, antigo IFPE Campus Pesqueira).

Em 2005, ao chegar numa recepção de um estabelecimento hoteleiro, diante de uma reportagem sobre povos do Xingu que passava no televisor daquele estabelecimento, esse autor presenciou, com espanto, uma das pessoas presentes naquele local exclamar: "Isso que é índio! Vive na mata! Não são como esses Xukuru de Ororubá!”.

Esse espanto inicial do autor - por uma imagem preconceituosa construída pelo homem branco - foi se transformando num desejo de conhecer mais sobre o povo Xukuru. Hoje, no momento em que o IFPE Campus Pesqueira concentra a quantidade de cem indígenas, sendo sessenta e três nos cursos superiores e o restante em outras modalidades de ensino (LUIZ; LIMA, 2018); em que existem núcleos dentro da instituição que priorizam o estreitamento de laços de diversas ordens com os povos indígenas e quilombolas; em que jornalistas da instituição se propõem a fazer matérias sobre esses povos; em que há, por esse autor, uma apropriação da teoria da AD no questionamento das evidências de sentido, determinado discurso constitutivo de exclamações como aquela de 2005 pode ser desnaturalizado. Segundo Borges (2014, p. 79),

Esse discurso parece natural, evidente, por efeito da ideologia. A interpelação ideológica é tão eficaz que não se questionam os sentidos que são produzidos. Por exemplo, está naturalizado que os povos indígenas "são preguiçosos", "são ladrões", "são invasores de terras dos fazendeiros", "deixam de ser índios quando vêm para a cidade". 
A sequência discursiva (SD) abaixo foi recortada do vídeo institucional Sou IFPE: abril indígena (2017). O vídeo traz o depoimento de uma aluna Xukuru - IFPE, Bacharelanda em Enfermagem.

\begin{abstract}
Sequência discursiva 1 (SD1)
(...) se você for avaliar, historicamente falando, todas as conquistas dos povos indígenas foram através da luta. Porque todo mundo se junta, unifica e a gente consegue. E aí a gente luta cada dia. A gente luta através dos movimentos estudantis, luta através de vir para cá, acordar cedo todos os dias, assistir aula, ou através dos projetos de extensão que atualmente eu desenvolvo um projeto de extensão com o meu povo. (...) A gente tenta somar. Também não só trazer os conhecimentos de lá para cá, mas também levar daqui para lá. A gente aprende, desde a escola na aldeia, que a gente sozinha não consegue nada. (...) se não tivesse existido a criação de políticas públicas para a cota, por exemplo, se não tivesse essa interiorização do ensino, seria muito mais complicado como era antes. (...) eu busco agarrar cada oportunidade que eu tenho: se tenho chance de ser monitora, vou ser monitora; se tenho chance de ser extensionista, vou ser extensionista. E tentar me aperfeiçoar para contribuir mais tarde para o meu povo (...) (Sujeito-aluno Xukuru 1).
\end{abstract}

No dizer "todas as conquistas (...) foram através da luta. (...) a gente luta cada dia. A gente luta através (...)" (SD1) do Sujeito-aluno Xukuru 1 há um regime de repetibilidade em que se imbricam os discursos de lutas e conquistas. A memória discursiva do povo Xukuru é permeada por ações e marcos históricos calcados em atos de bravura, coragem, resistência e, até mesmo, no não temer a morte pela causa indígena. O cacique Xicão foi assassinado em 1988, por conta da luta pela demarcação e ocupação do território Xukuru. Hoje, ainda é memorável um de seus depoimentos realizado anos antes da sua morte:

Estão querendo fazer comigo mesmo aquilo que fizeram com Antônio Conselheiro, Che Guevara e com outras lideranças, mas não tem nada. Se esse for meu destino, for autorizado pela natureza, por Deus, estou disponível. Não vou me recuar (XICÃO XUKURU, 1998).

O funcionamento do discurso de Xicão revela a mesma trilha inevitável de heróis históricos que foram imolados, sacrificados por uma causa maior. No seu dizer, além da permissão do destino e de Deus, a natureza (a mãe natureza, os encantados) ${ }^{5}$

\footnotetext{
${ }^{5}$ A partir de uma observação de rituais na festa de São João na Vila de Cimbres, território Xukuru, Silva (2008) descreve a relação desse povo com os encantados; "Voltam para o salão do Centro Social, onde continuam dançando o Toré até perto de meia-noite, quando vão para um local, nas proximidades da Vila onde está uma pedra plana, chamada Laje do Conselho. Naquele local, em silêncio, ficam esperando os conselhos dos Encantados, dos antepassados falecidos. Ocorrem
} 
pode autorizar, permitir que ele seja assassinado. O discurso heroico de luta, do não retroceder mesmo que algo de terrível aconteça, funciona como uma antecipação do sujeito Xicão para nortear o seu povo nas lutas vindouras pelas retomadas das terras do Ororubá. Segundo Orlandi (1998, p. 76),

Todo sujeito (orador) experimenta o lugar do ouvinte a partir de seu próprio lugar de orador, constituído pelo jogo das formações imaginárias (a imagem que faz de $x$, de si mesmo, do outro). Cada um 'sabe' prever onde seu ouvinte o espera”. Esta antecipação do que o outro vai pensar é constitutiva de todo discurso.

O funcionamento discursivo do dizer de Xicão difere dos discursos midiáticos de heroicização estudados por Grigoletto e De Nardi (2015, 2016), isso, principalmente, quanto à politização, à história de lutas e resistências que constituem o discurso do povo Xukuru. Contudo entendemos que possam existir pontos em comum entre eles, como o do apagamento de contradições. No discurso de heroicização, segundo as autoras, os sujeitos e discursos são despolitizados. O fato de eles se tornarem heróis é oriundo do movimento do apagamento de contradições, de uma aparente inexistência de espaços para questionamentos à heroicização desses sujeitos.

\footnotetext{
Nos diferentes olhares que se colocam sobre o herói, o que aparece como recorrência é o fato de ser ele uma fonte perene de identificações imaginárias e de identidade coletiva, desde as antigas epopeias, quando se estabelece sua ligação estreita com o mito nacional, até a contemporaneidade, quando ele assume aspectos peculiares em representações culturais fortemente mediadas pelos discursos midiáticos, com sua propensão à espetacularização (GRIGOLETTO; DE NARDI, 2015, p. 120).
}

No depoimento do sujeito-aluno Xukuru 1, o falar sobre união, unificação e conquista é constituído de uma memória discursiva que retrata um processo de mudança de posição histórica do sujeito Xukuru do Ororubá. Antes da Constituinte de 1988, da organização do povo pelo cacique Xicão, os Xukuru se identificavam como caboclos. Eles eram assujeitados ao discurso dos fazendeiros que tomaram posse das terras do Ororubá. Segundo Pêcheux (1988, p. 161), “a interpelação do indivíduo em sujeito de seu discurso se efetua pela identificação (do sujeito) com a formação aos presentes, que escutam atentamente" (SILVA, 2008, p. 145). 
discursiva que o domina (isto é, na qual ele é constituído como sujeito)”. A mudança de posição de sujeito caboclo para a de sujeito Xukuru pelos indígenas do Ororubá foi uma das conquistas de Xicão. "O objetivo de Xicão era mostrar para o povo Xukuru e dizer para o povo Xukuru quem era o povo Xukuru”6 (SANTA, 2008). Segundo Silva (2008),

Em suas mobilizações, os Xukuru constantemente recorreram às memórias como forma de garantir as reivindicações de seus direitos, dentre eles primordialmente a demarcação do território, ocorrida em 2001. Nos relatos das memórias orais dos Xukuru, encontramos lembranças de um tempo em que as pressões dos fazendeiros não eram tão intensas. Nascida em Brejinho e atualmente moradora na vizinha Aldeia Cana Brava, "Dona" Lica recordou que sua mãe dizia ter ouvido dos antepassados que não existia documento de propriedade da terra. A entrevistada lembrou também ter ouvido sua mãe falar que o local onde nasceu, sem a presença ostensiva de fazendeiros, possuía muita água e matas, proporcionando fartura de fruteiras. Ela e mais ainda seus antepassados viviam do que coletavam da natureza (SILVA, 2008, p. 183).

Os efeitos de sentido do dizer "eu busco agarrar cada oportunidade" (SD1) remetem - em outras condições de produção, em uma posição ressignificada - ao grito de conclamação do Cacique Marcos, filho de Xicão (e à resposta do seu povo) sobre a porteira demarcatória da entrada do território Xukuru. Um ato emblemático do início da caminhada Xukuru à cidade de Pesqueira para a finalização de sua assembleia todo dia 20 de maio de cada ano: “- E diga ao povo que avance! - Avançaremos!”’.

O dizer "A gente aprende, desde a escola na aldeia, que a gente sozinha não consegue nada" (SD1) produz um efeito de sentido de que, além dos dizeres enunciados nos rituais, nas celebrações, nas festas, nas assembleias e no cotidiano Xukuru, o sujeito Xukuru é constituído por um discurso que é mobilizado nas escolas do seu povo.

A função da escola é formar guerreiros! E é por isso que ela existe! (...) formando guerreiros que lutam pela terra, pelos direitos, participam ativamente da vida político-social do povo, valorizam o ritual e as festas, fazendo com que o projeto de vida Xukuru se torne sólido e garantido (POVO XUKURU DO ORORUBÁ, 2010, p. 13).

\footnotetext{
${ }^{6}$ Palavras do vice-cacique Zé de Santa, José Barbosa dos Santos, no documentário Xicão Xukuru (2008).

Discurso do Cacique Marcos na $17^{\text {a }}$ Assembleia Xucurú-Limoalaygo Toype (2018). Fonte: $<$ https://www.youtube.com/watch?v=Jd2s-DnwWuc>. Acesso em 13/09/2018.
} 
Como nos diz Courtine (2009, p. 105), o trabalho da memória discursiva está relacionado "à existência histórica do enunciado no interior de práticas discursivas regradas por aparelhos ideológicos”. Assim, o dizer do Sujeito Xukuru é constituído de materialidade discursiva, dos ditos em outras condições de produção, em outros tempos, em outros lugares. O sujeito indígena vai sendo enredado no corpo da cidade como nos diz Borges (2013) - fora dos domínios Xukuru, no corpo da instituição de ensino, no processo de sua formação como bacharel em Enfermagem.

O discurso de luta Indígena se ressignifica, toma novos sentidos. Temas como políticas públicas afirmativas e interiorização de ensino, monitoria, extensão vão sendo incorporados ao discurso do Sujeito Xukuru e sua luta em outras espacialidades e temporalidades.

A seguir, descreveremos o vídeo Movimento nacional em defesa do programa bolsa permanência indígena e quilombola (PROGRAMA, 2018). Esse vídeo retrata a luta de estudantes indígenas do IFPE Campus Pesqueira pelo direito irrestrito ao Programa Bolsa Permanência e para que essa bolsa se torne uma Política de Estado e não de Governo, não ficando à mercê de cortes governamentais que afetem estudantes indígenas e quilombolas de todo o Brasil.

Todos os sujeitos que aparecem no vídeo são alunos Xukuru do Instituto Federal de Pernambuco. O vídeo se inicia com uma aluna colocando adornos em outra aluna. Na segunda cena, aparecem os alunos dançando o Toré ${ }^{8}$. Alguns estão vestidos com camisetas do evento abril indígena do IFPE, outros com camisetas com imagem de Xicão, com colares e barretinas ${ }^{9}$. Seguem-se quatro cenas onde os alunos fazem seus depoimentos sobre o movimento, um deles se apresenta com o tronco e os braços com traços da pintura corporal Xukuru. Na penúltima cena, os alunos aparecem com cartazes sobre o movimento. Na oitava e última cena, os alunos exclamam em

\footnotetext{
${ }^{8}$ Sendo um ritual que une dança, religião, luta e brincadeira, o Toré, Segundo Grünewald (2008), está "totalmente incorporado ao movimento indígena no Nordeste como forma de expressão política (GRÜNEWALD, 2008, p. 43)". Em meados do século XX, a exibição da dança do Toré passou a ser uma forma de atestar a indianidade dos índios no Nordeste pelos inspetores do Serviço de Proteção aos Índios (SPI). Desde então, "esta prática cultural passou, assim, a circular ideologicamente como sinal diacrítico dessa ampla indianidade e, até hoje, é ensinada de grupos reconhecidos a grupos que pleiteiam reconhecimento indígena em todo o Nordeste. Mesmo grupos que apresentavam outras manifestações culturais (outras danças) incorporam o Toré (ou a retórica do Toré) como padrão de etnicidade (GRÜNEWALD, 2008, p. 44).

${ }^{9}$ Chapéu que é símbolo do Povo Xukuru. Ele é feito de palha de Ouricuri (palmeira de nome científico Syagrus coronata) e de fibra de Coroá, também chamada de Caroá ou Gragoatá (Bromélia cujo nome científico é Neoglasiovia variegata).
} 
uníssono: bolsa permanência já! Nesse momento, aparece abaixo da tela: \#bolsapermanênciajá.

Antes de apresentarmos e analisarmos as sequências discursivas do vídeo, trataremos de descrever as suas condições de produção e mais precisamente a conjuntura político-social que o determinou.

Desde o início do ano de 2018, o acesso ao programa foi bloqueado. Criado em 2013, no Governo Dilma Rousseff, o programa vinha garantindo o acesso à educação a estudantes indígenas e quilombolas. Após o golpe da Presidenta Dilma, o governo de Michel Temer passou a fazer cortes de bolsas e diminuição de ações afirmativas nas políticas públicas.

Nas Universidades públicas e Institutos Federais do país, o acesso a indígenas, pardos, pretos e estudantes de escolas públicas foi ampliado pela Lei de Cotas - Lei no 12.711/2012 - que estabeleceu 50\% (cinquenta por cento) a esse público. Mas vale ressaltar que foi no Governo Lula (2003-2010) que houve, paulatinamente, uma significante expansão das universidades com apoio a Planos de Reestruturação e Expansão das Universidades Federais (Reuni) e a criação e ampliação de ações afirmativas. Segundo Duarte (2014)

É importante salientar que a definição de ações afirmativas não se confunde com a de cotas. Aquelas seriam o gênero e estas a espécie. Toda contratação ou promoção preferencial de membros de grupos discriminados, seja por meio de cotas, bolsas de estudo, vantagens, medidas de proteção ou reparações financeiras, são abarcadas pelo conceito de ação afirmativa (DUARTE, 2014, p. 5).

Após o ano de 2016 - ano do "Impeachment" da Presidenta Dilma - além do retrocesso em negar e tentar suplantar as conquistas sociais alcançadas por essas políticas implementadas nos governos de Lula e Dilma, o Governo Temer - sucessor do Governo Dilma - e sua base política têm tomado como primazia, no âmbito da educação, ações em torno de implementações da Reforma do Ensino Médio, da Base Nacional Comum Curricular e do sucateamento das universidades públicas. Essas ações fazem parte de uma agenda política neoliberal que diferem de ações de fortalecimento das instituições públicas de ensino, autônomas e de caráter estatal. Abreu (1999) assim descreve a base das políticas conservadoras neoliberais: 
A fonte teórica dessas políticas conservadoras é a teoria econômica, mais especificamente o campo da Economia da Educação. Na visão de certos autores, a universidade é despida de toda a sua complexidade como instituição social e é reduzida a uma unidade produtiva, devendo ser financiada e avaliada segundo critérios quantitativos de custo-benefício. Seu produto é o capital humano incorporado nos profissionais formados. Os únicos critérios válidos para se medir a eficiência, a qualidade e a produtividade são os critérios de mercado. A educação é concebida como mercadoria, ofertada e demandada em seu mercado. Os demandantes são os estudantes, as empresas e o governo, enquanto as instituições educacionais são as ofertantes (ABREU, 1999, p. 62).

Assim, os cortes efetuados no Programa Bolsa Permanência são determinados por uma agenda neoliberal que o Governo Temer vem acatando no trato com a educação pública do país.

Feita a descrição dos fatos relacionados ao que levou à existência do vídeo Movimento nacional em defesa do programa bolsa permanência indígena e quilombola (PROGRAMA, 2018), apresentaremos as sequências discursivas recortadas desse vídeo. A sequência discursiva 2 traz o dizer do Sujeito-aluno Xukuru 2 proferido em territórios Xukuru. É um dizer de pertencimento do sujeito ao povo Xukuru e de visão da necessidade da bolsa para outros indígenas na mesma posição que ele. A sequência 3 apresenta o dizer do sujeito 2 realizado no Instituto Federal de Pernambuco Campus Pesqueira. O sujeito 2 mobiliza dizeres com os significantes desrespeito, desestímulo, adaptação e merecimento.

Sequência discursiva 2 (SD2)

Sou Xukuru do Ororubá, índio... Essas pessoas que precisam, além de mim, índios das capitais que precisam dessa bolsa permanência para transporte, alimentaçãos e moradia, para que a gente chegue no final do curso com êxito (Sujeito-aluno Xukuru 2).

Sequência discursiva $3\left(\mathrm{SD}_{3}\right)$

O que acontece hoje é um tremendo desrespeito com os povos indígenas e quilombolas, considerando o fato de que com essa diminuição da oferta de bolsa, os estudantes serem desestimulados a se manterem na faculdade e novos estudantes também são desestimulados a entrar na faculdade. A gente não pode deixar isso acontecer. Porque nós devemos considerar o deslocamento desses estudantes, nós devemos considerar a questão da adaptação ao novo ambiente e existem cursos que são integrais. Então além de não ter como se manter devido a sua situação socioeconômica, eles estão passando por todo um processo de adaptação. E a oferta dessas bolsas diminuída, fazendo com que a gente tenha que falar quem merece mais, isso é outra forma de desrespeito com os indígenas. Porque nós não podemos dizer que um povo precisa mais da oferta desse dinheiro, dessa permanência, do que os outros. Então, isso aí é outra forma de desrespeitar a comunidade indígena e quilombola (Sujeito-aluno Xukuru 3). 
O enunciado Sou Xukuru do Ororubá, índio (SD2) é constituído do dizer não sou caboclo; é uma marca de um não assujeitamento ao discurso dos fazendeiros da região. É a partir dessa posição, e por ela, que o Sujeito-aluno Xukuru 2 se coloca na luta pelos seus direitos referentes à continuação da bolsa permanência. No entanto, entendemos que o significante índio - nessas condições de produção do discurso de luta e de identificação como sujeito Xukuru - pode ser considerado como uma marca de atravessamento do discurso sobre o indígena pelo não indígena de forma pejorativa. Um significante que ainda perdura no dizer do sujeito-aluno Xukuru 2. Daniel Munduruku (2017), escritor indígena Munduruku, no início de sua fala na $63^{\underline{a}}$ Feira do Livro de Porto Alegre, declara que quando alguém chama o outro de índio, "não ofende só uma pessoa, ofende culturas que existem há milhares de anos. Esse olhar linear empobrece nossa experiência de humanidade" (MUNDURUKU, 2017, p. 1). Para Batalla (1971):

A categoria de índio, com efeito, é uma categoria supra-étnica que não denota qualquer conteúdo específico dos grupos que abarca, mas uma relação particular entre eles e outros setores do sistema global de que os índios formam parte. A categoria de índio denota a condição de colonizado e faz referência necessária à condição colonial (BATALLA, 1971, p. 110).

Na dissertação O imaginário em torno do "ser índio" no discurso do/sobre o sujeito-indígena: entre o assujeitamento e a resistência, André Silva (2017), ao analisar os discursos sobre os povos indígenas Fulni-ô e Potiguara, dos estados da Pernambuco e da Paraíba respectivamente, compreende que:

o discurso do indígena é atravessado pelo discurso sobre o indígena, no qual falar sobre o que é ser indígena implica falar sobre o outro, o homem "branco", mobilizando, portanto, sentidos que constituem o imaginário social sobre o índio. Dessa maneira, a identidade indígena está em relação com a alteridade, com o não-indígena, assim como com outros povos indígenas. A resistência indígena é produzida através da identificação como índio, pois, mesmo tendo que estar assujeitado ao Estado, esses povos continuam suas práticas culturais. (SILVA, 2017, p. 8).

Há um imaginário dominante sobre os povos indígenas em torno do significante unificador "índios” na sociedade. Eles são vistos como uma totalidade, como um único 
povo, uma só cultura. O dizer povos indígenas ( $\left.\mathrm{SD}_{3}\right)$ do Sujeito-aluno Xukuru 3 tem um efeito de um gesto político de afirmação das multiplicidades de culturas existentes nesses povos e de lutas compartilhadas entre eles. Nessa posição discursiva, constituída de discursos indígenas e acadêmicos, defender essas lutas é unir forças e compreender as necessidades atuais de além de mim (SD2) e as futuras necessidades de novos estudantes ( $\mathrm{SD}_{3}$ ); é se colocar num lugar longe do imaginário proveniente do efeito de evidência de "pureza”, construído e cristalizado pelo discurso colonial.

\begin{abstract}
No Brasil os povos indígenas estão presentes em diversos lugares com muitas características semelhantes, mas, cada povo com sua história e cultura diferentes, essa é, em larga dimensão, uma riqueza. [...] As sociedades indígenas brasileiras, devido a diversas formas de intervenções da sociedade majoritária, possuem, historicamente, com exceção de alguns grupos isolados, relações com não indígenas e entre as diferentes etnias, ou seja, o imaginário de etnia pura, culturalmente tradicional e intocada faz parte do imaginário ocidental sobre a alteridade produzida pelo efeito de evidência da ideologia colonial, que tende a gostar dos povos indígenas apenas como "puros", enfeitados com penas, pintados, aldeados. (BORGES, 2017, p. 252).
\end{abstract}

As ações políticas que afetam os sujeitos indígenas nem sempre afetam com os mesmos sentidos, da mesma forma ou na mesma proporção, os sujeitos da sociedade não indígena. Desmatamentos, construções de estradas e hidrelétricas que podem dizimar um povo indígena, podem não afetar, diretamente ou instantaneamente, povos não indígenas.

Ao restringir o número de bolsas permanência e colocar sob responsabilidade de uma comissão a criação de critérios de exclusão/inclusão para obtenção das bolsas pelos estudantes indígenas, o Ministério de Educação (Mec) do Governo Temer transfere responsabilidades, eximindo-se da culpa nos cortes no Programa. Os dizeres tremendo desrespeito e nós não podemos dizer que um povo precisa mais (...) que os outros $\left(\mathrm{SD}_{3}\right)$ desnaturalizam o sentido de responsabilidade que o discurso do Mec imprime para transferir as atribuições a uma futura comissão de indígenas que tratará do fato. Os sujeitos $S_{2}$ e S3 são interpelados por discursos de luta e resistência que se materializam na dança do Toré, nos gestos de se ornarem e se pintarem. Eles se subjetivam na posição de defesa de causas históricas e atuais atreladas ao povo Xukuru.

Pensando-se a subjetividade, podemos então observar os sentidos possíveis que estão em jogo em uma posição-sujeito dada. Isso porque, como sabemos, 
o sujeito, na análise de discurso, é posição entre outras, subjetivando-se na medida mesmo em que se projeta de sua situação (lugar) no mundo para sua posição no discurso. Essa projeção-material transforma a situação social (empírica) em posição-sujeito (discursiva). Vale lembrar que sujeito e sentido se constituem ao mesmo tempo, na articulação da língua com a história, em que entram o imaginário e a ideologia (ORLANDI, 1999, p. 17).

\section{Considerações finais}

A partir de sequências discursivas recortadas de vídeos institucionais, que marcam a presença de sujeitos estudantes indígenas Xukuru de Ororubá na luta pela permanência de seus direitos em uma instituição federal de ensino, este artigo tratou de analisar o discurso político desses sujeitos ante o dizer do "já constituído" sujeito Indígena, com o seu dizer em um lugar outro, fora das terras demarcadas na Serra do Ororubá.

Vimos que o discurso político que os constitui, nessas condições de produção, foi construído em torno da resistência do povo Xukuru, na luta pela manutenção e retomada do seu território das mãos dos fazendeiros da região.

Em nosso trabalho, sem a pretensão de fechamento, observamos que a retomada do território Xukuru, legitimada pela Constituição de 1988, a afirmação do Indígena não mais como caboclo, a inserção do estudante Xukuru em instituições de ensino técnico e superior, e a posição da comunidade de estudantes indígenas diante dos últimos acontecimentos políticos no país são constituídos por um discurso de luta, de conquista; dizeres mobilizados por memórias discursivas e pela leitura de arquivos que se tornaram memoráveis para este povo e para os povos indígenas no Brasil.

Entendemos que o discurso do Sujeito Xukuru vai ganhando novos sentidos em condições de produção diversas, mas ainda o que é memorável nos saberes dos discursos fundantes permanece mobilizando sentidos e sujeitos. Isso em razão da constante luta política desse povo na estrutura e na conjuntura político-econômicosocial nacional vigente. 


\section{Referências}

ARAUJO, Zelinda. Depoimento. In : Xicão Xukuru. PEREIRA, Nilton. Recife: TV Viva, 1999.

BATALLA, Guillermo Bonfil. El concepto de índio en América: una categoría de la situación colonial. Anales de Antropología, v. 9, p. 105-124. México: UNAM, 1972.

BORGES, Á. A. C. O corpo indígena enredado no corpo da cidade: efeitos do/no discurso. In: FERREIRA, C. L; INDURSKY, F.; MITTMANN, S.. (Org.). O acontecimento do discurso no brasil. Campinas: Mercado de letras, 2013, v. I, p. 249-262

BORGES, Á. A. C. Relacão sujeito indígena/cidade: Análises para a construção de um objeto de pesquisa. Rua (UNICAMP) , v. 20/II, p. 73-95, 2014.

. No detalhe do traço: ritos, cores e resistência. In: ZOPPI FONTANA, M. G. ; FERRARI, A. J. Mulheres em discurso: identificações de gênero e práticas de resistência. V.2. Campinas: Pontes, 2017.

COURTINE, Jean-Jacques. Análise do discurso político: o discurso comunista endereçado aos cristãos. São Carlos: EduFSCar, 2009.

DUARTE, A. C. A Constitucionalidade das Políticas de Ações Afirmativas. Brasília: Núcleo de Estudos e Pesquisas/CONLEG/Senado, abril/2014 (Texto para Discussão no 147). Disponível em: <www.senado.leg.br/estudos>. Acesso em: 13 set. 2018.

GRIGOLETTO, E.; DE NARDI, F. S. A (des)construção do "herói" nos discursos sobre o mensalão: o caso Joaquim Barbosa. Desenredo, Vol. 11, no 1, jan - jun 2015, p. 118 - 133. Disponível em:

http://www.upf.br/seer/index.php/rd/article/view/4986/3446. Acesso em: 19 nov. 2015 GRIGOLETTO, E. ; DE NARDI, F. S. . (Des)politização e resistência no funcionamento dos processos de heroicização construídos pelo discurso da mídia. In: Evandra Grigoletto; Fabiele Stockmans De Nardi. (Org.). A Análise do Discurso e sua história: avanços e perspectivas. 1ed. Campinas: Pontes editores, 2016, v. 1, p. 271-282.

GRÜNEWALD, R. A. Toré e jurema: emblemas indígenas no nordeste do Brasil. Ciência e cultura. Vol. 6o, no 4, Out, 2008, p. 43-45.

LUIZ, Jorge; LIMA, Aline. Presença indígena na educação profissional. In : Acontece IFPE, Vol. 1, Ago-Set, 2018, p. 18-23. 
MELO, R. A. A crise da universidade pública e o neoliberalismo. Princípios, Vol. 41, Mai-Jul, 1996, p. 62-65. Disponível em: <http://revistaprincipios.com.br/artigos/41/cat/1647/a-crise-da-universidadep\&uacute blica-e-o-neoliberalismo-.html>. Acesso em: 13 set. 2018.

MUNDURUKU, Daniel. “Eu não sou índio, não existem índios no Brasil”. In: O Nonada: Jornalismo Travessia. Disponível em :

<http://www.nonada.com.br/2017/11/daniel-munduruku-eu-nao-sou-indionaoexistem-indios-no-brasil/>. Acesso em: 13 set. 2018.

ORLANDI,Eni. Ciências da Linguageme Política: Anotações ao pé das Letras. Campinas : Pontes, 2014.

Discurso e argumentação: um observatório do político. Fórum Linguístico. Florianópolis: n.1, 1998. Disponível em:

<https://periodicos.ufsc.br/index.php/forum/article/view/6915/6378>. Acesso em: 30 nov. 2017.

. Do sujeito na história e no simbólico. In: Revista Escritos nº 4: contextos epistemológicos da análise do discurso. Campinas: LABEURB, 1999.

POVO XUKURU DO ORORUBÁ. Plantando a memória do Nosso povo e colhendo os frutos da nossa luta:. O projeto político pedagógico das escolas xukuru. Recife: Centro de Cultura Luiz Freire, 2005.

PÊCHEUX, Michel. Análise automática do discurso. Tradução de Eni P.Orlandi. In: GADET, Françoise; HAK, Tony (Org.). Por uma análise automática do discurso: uma introdução à obra de Michel Pêcheux. 2. ed. Campinas: Unicamp, 1993. p.61-161. Tradução de: Analyse automatique du discours, 1969.

Ler o arquivo hoje. In: ORLANDI, Eni Puccinelli. (Org.). Gestos de leitura: da história no discurso. 3. ed. Campinas: Editora da UNICAMP, 2010, p.49-59.

. Semântica e Discurso; uma crítica à afirmação do óbvio (1975). Campinas, Ed. da UNICAMP, 1988.

ROMÃO, L.M.S.; LEANDRO-FERREIRA, M.C.; DELA-SILVA, S. (Orgs.) Arquivo. In: MARIANI, B.; MEDEIROS, V.; DELA-SILVA, S. Discurso, arquivo e... Rio de Janeiro: 7Letras, 2011. 
PROGRAMA bolsa permanência indígena e quilombola. Produção: Jorge Luiz. Edição de video: Keise Nascimento - Birô de Comunicação, IFPE Campos Olinda. Pesqueira: IFPE Campus Pesqueira, 2018. Disponível em:

<https://www.facebook.com/ifpecampuspesqueira/videos/1869565266440433/>.

Acesso em: 13 set. 2018.

SANTA, José. Depoimento. In: XICÃO Xukuru. Direção: Xenupres Herdeiro do Mandaru et e tal. Produção: Hamilton Costa Filho. Recife: Cabra quente produções, 2008. Mini DVD (16 min.)

SILVA, Edson. Índios Xukuru: a história a partir das memórias. História Unisinos.v. 15 n. 2, p.182-194, 2011.

Xucuru: memórias e história dos índios da Serra do Ororubá (Pesqueira/PE), 1959-1988. Tese de Doutorado em História Social. Campinas, UNICAMP, 2008.

SILVA, André. O imaginário em torno do "ser índio" no discurso do/sobre o sujeitoindígena: entre o assujeitamento e a resistência. Recife : UFPE, 2017.

SOU IFPE abril indígena. Jaqueline Lopes. Direção: Rafaela Vasconcellos. Pernambuco: Assessoria de Comunicação do IFPE, 2017. 3’48”. Son. Color. Disponível em: <https://www.facebook.com/hashtag/canalifpe>. Acesso em: 13 set. 2018.

XICÃO Xukuru. Direção: Nilton Pereira. Recife: Tv Viva,1998. (20 min). Son. Color.

XICÃO Xukuru. Direção : Xenupres Herdeiro do Mandaru et e tal. Produção: Hamilton Costa Filho. Recife: Cabra quente produções, 20o8. Mini DVD (16 min.). Son. Color.

\section{Recebido em 13/09/2018.} Aprovado em 19/11/2018. 